\title{
Laws of the Universe or Laws of Physics
}

\author{
Patrice F Dassonville \\ Laws of the Universe, France \\ Submission: May 25, 2018; Published: August 10, 2018 \\ "Corresponding author: Patrice F Dassonville, Laws of the Universe, 68 La Croisette, 06400 Cannes, France, Tel: 0493435638, \\ Email: patrice.f.dassonville@gmail.com
}

\section{Abstract}

It seems crucial to differentiate these two expressions: laws of the Universe and laws of physics. A law is supposed to be invariable, definitive, intangible, whereas there are many examples of evolution of physical laws; in such a way that we talk about the diachrony of physical laws. Diachrony, from the Greek dia (through), is a term of linguistics: it means change with time, not because of time, since we know that time is not a phenomenon [1].

\section{Introduction}

A modeling is an arrangement with physical reality, but not a substitute for it. However, it allows a description, a quantification, an evaluation, and a certain prediction. The observation, the experiments, the replication of findings, and the mathematical models of physics, lead to the formulation of laws. Therefore, the physical laws depend on the concepts and the models that are used; they depend on the progress of research and on the progress of thinking in general. A physical law is not discovered in nature, instead, it follows from a construction of the mind: thus, the observation of nature and the modelings lead to physical laws.

\section{The Diachrony of Physical Laws}

These remarks provide grounds for making the following observations:

a) The accuracy of laws is not absolute; they do their best (sic pro optima), but they inevitably convey inaccuracies.

b) The physical laws are not immutable. For Einstein, laws are only temporary solutions to our conceptions of reality [2].

The concepts and the models evolve independently of time; this evolution leads to changing laws. However, this does not cast shadow upon the genius of their initiators; to claim a century later that Einstein, Darwin, or Freud were mistaken is an anachronism. For these reasons, neither nature nor the Universe obeys our laws; They are not compelled to abide by our laws; they do not operate according to a law, ex lege in Cicero [3]; Our physical laws provide certain descriptions and they make some predictions possible, but they do not prescribe anything. The main feature of our physical laws is that they provide a temporary description rather than a permanent imperative. Repeated train or aircraft crashes often make people conjecture some law about series of accidents, but this is a mistake, because the essence of a law is to predict, while these events are not predictable. The economic cycle is not a law of economics, because collapse is unpredictable. Moreover, economists and politicians are unable to predict crises; they do not even agree among themselves about how to find a way out of a crisis. The principle of Roman law, lex imperat (the law dictates), is not true in physics; so, the ambition to circumscribe the Universe (totum, the whole, the totality) with a corpus of immutable laws within a final theory is utopic (i.e., in no place) and uchronic (i.e., never, at no time). Einstein gave up looking for a global picture of the Universe, explaining that he was not disavowing a principle, but applying a method [2].

More thorough observations, more accurate measurements, more advanced mathematical models, and new theories will lead to changing laws, to the rejection of some laws and the introduction of new laws. Some of the current laws will be done away with or modified like Kepler's laws. The first law of the German astronomer Johannes Kepler (1571-1630) provides a simple illustration. It says that the Earth follows an elliptical orbit around the Sun. This law overturned the then consensus on astronomical knowledge. However, it turned out later that astronomy had to make some corrections, among which we find: The orbit followed by the Earth is disrupted by the revolution of the Moon; the Earth is shaken by the Moon, so that the ellipse is sinusoidal. In fact, it is the center of gravity of the couple EarthMoon that follows an elliptical curve.

a) Moreover, the laws of physics have been developed with concepts of time and space, which are prevalent, although they remained undefined. Therefore, this quite legitimately raises a question concerning the progressive precarity of existing laws in favors of new ones which may not involve time and/or space, but some more efficient models, with more effective parameters. 
b) Due to an infinitesimal deceleration, the center of gravity does not return to exactly the same place after one revolution: the curve is a converging spiral ellipse.

c) In conclusion, the curve followed by the Earth is a sinusoidal and converging spiral ellipse. This means that the accuracy of the Earth-Sun clock is limited.

\section{Conclusion}

Expressions such as laws of the Universe and laws of nature, The law of nature is in Cicero [3], are survivors from ancient divinations of Nature, which were considered superstitions by Lucretius [4]. These expressions are examples of epistemic immoderation which should be excluded from scientific semantics and replaced by more circumstantial expressions, such as laws of biology, laws of astronomy, laws of thermodynamics, laws of physics, or physical laws; provided that a physical law is always an interpretation, the consequence of an observation.

\section{References}

1. Dassonvillle P (2012-2017) L'inexistence du temps. The invention of time \& space.

2. Einstein A (1879-1955) Mein Weltbild. (How I see the world Flammarion - 2009).

3. Gaffiot F, Flobert P (2012) French Latin Dictionary Le Grand Gaffiot (Hachette - Paris 2012)

4. Lucretius (c.96-55 BC) (2010) Nature (la nature des choses -Gallimard 2010 - Translated in French by Jackie Pigeaud).

Your next submission with Juniper Publishers will reach you the below assets

- Quality Editorial service

- Swift Peer Review

- Reprints availability

- E-prints Service

- Manuscript Podcast for convenient understanding

- Global attainment for your research

- Manuscript accessibility in different formats

( Pdf, E-pub, Full Text, Audio)

- Unceasing customer service

Track the below URL for one-step submission https://juniperpublishers.com/online-submission.php 